\title{
Identifying a migrating stress front using apparent stress for an unplanned rock mass cave
}

\author{
LG Brown Laurentian University, Canada \\ MR Hudyma Laurentian University, Canada
}

\begin{abstract}
Throughout a mining environment, variations in geotechnical and stress conditions can lead to unplanned rock mass failure. For operations with microseismic monitoring capabilities, seismic event locations and source parameters can often provide significant insight into rock mass failure processes. This paper presents observed variations in the seismic source parameter, apparent stress, during an unplanned rock mass cave in a deep Canadian mine. Over the course of six months, the rock mass cave propagates upwards more than $75 \mathrm{~m}$, at more than 1,000 $\mathrm{m}$ depth below surface. Emphasis is placed on identifying zones of relatively high rock mass stress as the cave propagates upwards over time.
\end{abstract}

Keywords: unplanned caving, seismicity, apparent stress, rock mass stress, underground mining

\section{Introduction}

Unplanned caving of production stope backs, as discussed by Ran and Disley (2004), can pose a significant risk to the viability of underground mining operations. Such caving processes can be complex relative to those observed in primarily caving mines (i.e. block and sublevel caves), as they are subjected to mining-induced stress concentrations, seismic activity, and geological structures at depth (Ran \& Disley 2004). Within a rock mass cave, Duplancic and Brady (1999) suggest there are five sequential regions: a caved zone consisting of rock blocks which have fallen from the cave back (located at the base of the cave), an airgap, a zone of discontinuous deformation, a seismogenic zone, and a surrounding pseudo-continuous zone (intact rock mass). The seismogenic zone represents a transition between the failed (caved) and intact rock mass. The spatial definition of this zone is a function of many parameters, and varies in three dimensions throughout the caving process.

Significant stress variation is expected to occur throughout the seismogenic zone, similar to how mining-induced stresses vary throughout any mining environment. Seismic event locations can be used to infer the general spatial bounds of the seismically active (seismogenic) zone. However, considering event locations independently provides little insight into the relative stress conditions experienced throughout the caving rock mass. Ran and Disley (2004) describe a zone of stress concentration beyond the yield zone for unplanned stope back caves. The lack of confinement, due to the caved rock mass, pushes the stress concentration zone further upwards, causing significant expansion of the yield zone. As the yield zone expands over time, the zone of stress concentration migrates upwards.

With relatively increased stress conditions, the high stress front is where larger stress fracturing type seismic events are more likely to occur. This may not be of particular concern for planned caves, where the location of critical infrastructure and underground accesses have been designed distant from future cave propagation and associated rock mass failure. However, no such forethought is possible in the case of unplanned rock mass caves. When assessing damage due to unplanned caves in underground mines, and/or implementing mitigation measures, underground personnel needs to be kept away from the cave. For this reason, it is beneficial to further delineate the seismogenic zone in an effort to identify the high-stress front as it migrates over time. This paper demonstrates how the seismic source parameter apparent stress can be used to provide insight into a migrating stress front during an unplanned rock mass caving process. 


\section{$2 \quad$ Background}

Seismic events are ground motions related to dynamic rock mass failure. The relative location of seismic events over time can provide insight into the propagation of rock mass caves (e.g. Reyes-Montes et al. 2010; Duplancic \& Brady 1999). However, further examination of the seismic data, particularly with a focus on seismic source parameters, has been shown to add significant value in delineating rock mass caves and the caving process (e.g. Abolfazlzadeh \& Hudyma 2016; Glazer 2016; Hudyma et al. 2008). As this paper focuses on identifying stress concentrations within a rock mass, the seismic source parameter apparent stress is the primary consideration. Glazer (2016) and Abolfazlzadeh and Hudyma (2016) demonstrate significant value in applying apparent stress to seismic monitoring data recorded in caving mines.

Apparent stress is a model-independent parameter (Domanski \& Gibowicz 2008; Gibowicz et al. 1990, 1991), originally defined by Wyss and Brune (1968) as:

$$
\sigma_{a}=\mu\left(\frac{E}{\mathrm{Mo}}\right)
$$

where:

$$
\begin{aligned}
& \sigma_{a} \quad=\text { apparent stress }(\mathrm{Pa}) . \\
& \mu \quad=\text { shear modulus of rigidity of the source material }(\mathrm{Pa}) . \\
& E \quad=\operatorname{seismic} \text { energy }(\mathrm{J}) . \\
& M o \quad=\operatorname{seismsc} \text { moment }(\mathrm{Nm}) .
\end{aligned}
$$

As stress increases within a rock mass, seismic events typically radiate more seismic energy than expected (Simser et al. 2003; van Aswegan \& Butler 1993). Two independent seismic source parameters, seismic energy and seismic moment, are considered in the calculation of apparent stress (Equation 1). Increasing stress conditions store more energy while simultaneously increasing confining forces and reducing deformation (seismic moment). This enables apparent stress to be used as a proxy for increasing stress conditions in a rock mass (Brown \& Hudyma 2017). Other studies have drawn similar conclusions regarding apparent stress and rock mass stress (e.g. Brown et al. 2015; Young 2012; Hudyma et al. 2008; Simser et al. 2003; Mendecki 1993).

Figure 1 depicts an energy-moment relation for the entire seismic population associated with an unplanned rock mass cave. Individual seismic events are coloured according to apparent stress, with discrete colour changes corresponding to roughly a half an order of magnitude increase. As the radiated seismic energy increases for a given seismic moment (representing the same moment magnitude), the apparent stress increases. For many seismic moment values shown in Figure 1, the apparent stress of associated seismic events differs by two orders of magnitude. It is this measure of relative energy release per unit of deformation that is used to infer increasing rock mass stress conditions.

Apparent stress of mine seismic data typically exhibits a scale dependence. As the event size (moment) increases, apparent stress increases at a greater rate. This is particularly evident for the largest energy and moment seismic events (shown in orange and red in Figure 1). This further supports the notion that the tracking of the high-stress front may be important, as the largest magnitude seismic events are often also the largest apparent stress events. 


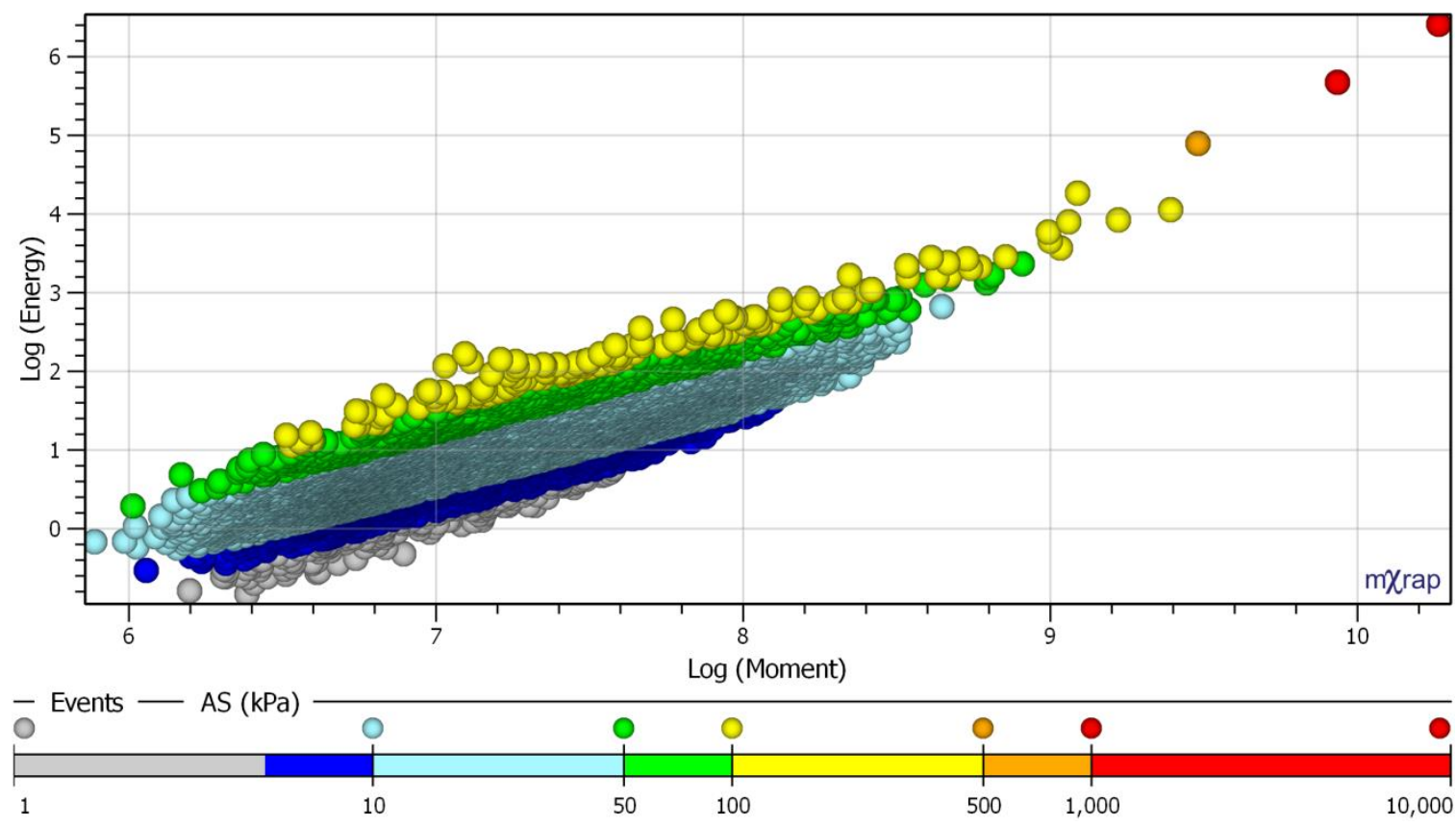

Figure 1 Energy-moment relation for a seismic population related to an unplanned rock mass cave in a deep Canadian mine. Events are coloured according to apparent stress, with discrete colour changes corresponding to roughly a half order of magnitude increase. Only events above the local microseismic monitoring system sensitivity $\left(M_{L}=-2.8\right)$ are considered

\section{$3 \quad$ Evaluating an unplanned rock mass cave}

In a typical caving mine, there are four stages during the rock mass caving process (Abolfazlzadeh \& Hudyma 2016; Butcher 2003): undercutting, cave initiation, cave propagation, and cave breakthrough to surface. This paper evaluates the final six months of seismic data associated with an unplanned rock mass cave in an underground mine. There is no breakthrough associated with this rock mass caving process, but rather a final cave stabilisation. The time period considered primarily consists of cave propagation, with the final month of data approaching cave stabilisation. Cave propagation refers to the continuous rock mass failure process in which the cave back, or in this case stope back, migrates upwards (Abolfazlzadeh \& Hudyma 2016; Duplancic \& Brady 1999).

Rock mass caves are three-dimensional, and can be challenging to conceptualise from two-dimensional representations. Figure 2 depicts the final six months of seismicity associated with an unplanned rock mass cave. One-month time intervals are used, and are consistently referred to throughout this paper by sequential values of one to six. Cave profile estimates for the current month and preceding month are outlined in red and black, respectively. These outlines are inferred from seismic event locations, and approximate the bottom of the seismogenic zone. Seismic events are coloured according to local magnitude, which can be crudely correlated to Richter magnitude, and only events above the local microseismic monitoring system sensitivity $\left(M_{L}=-2.8\right)$ are considered.

Variations in the rate of cave propagation are largely dependent on the surrounding mining activities (in particular, stope mucking or filling to stabilise the cave). The significant decrease in event rate associated with month three, for example, is likely a reflection of local mining operations (end of stope mucking), and not natural cave mechanics. In the absence of records specific to mining activities, variations in the cave propagation rate are not a primary consideration within this paper. 
Two mining levels are shown in Figure 2. The lower and upper level are referred to as Level 1 (L1) and Level 2 (L2), respectively, throughout this paper. The mucking level of the unplanned cave is an uncharacteristically large production stope located below L1 (i.e. L1 is the top sill of the stope). Left unfilled, the stope back was able to cave through the next mining level (between L1 and L2), and beyond. This paper focuses on the final six months of seismicity associated with the caving processes, in which the cave profile (as approximated by seismic event locations) reaches and exceeds L2 (Figure 2).

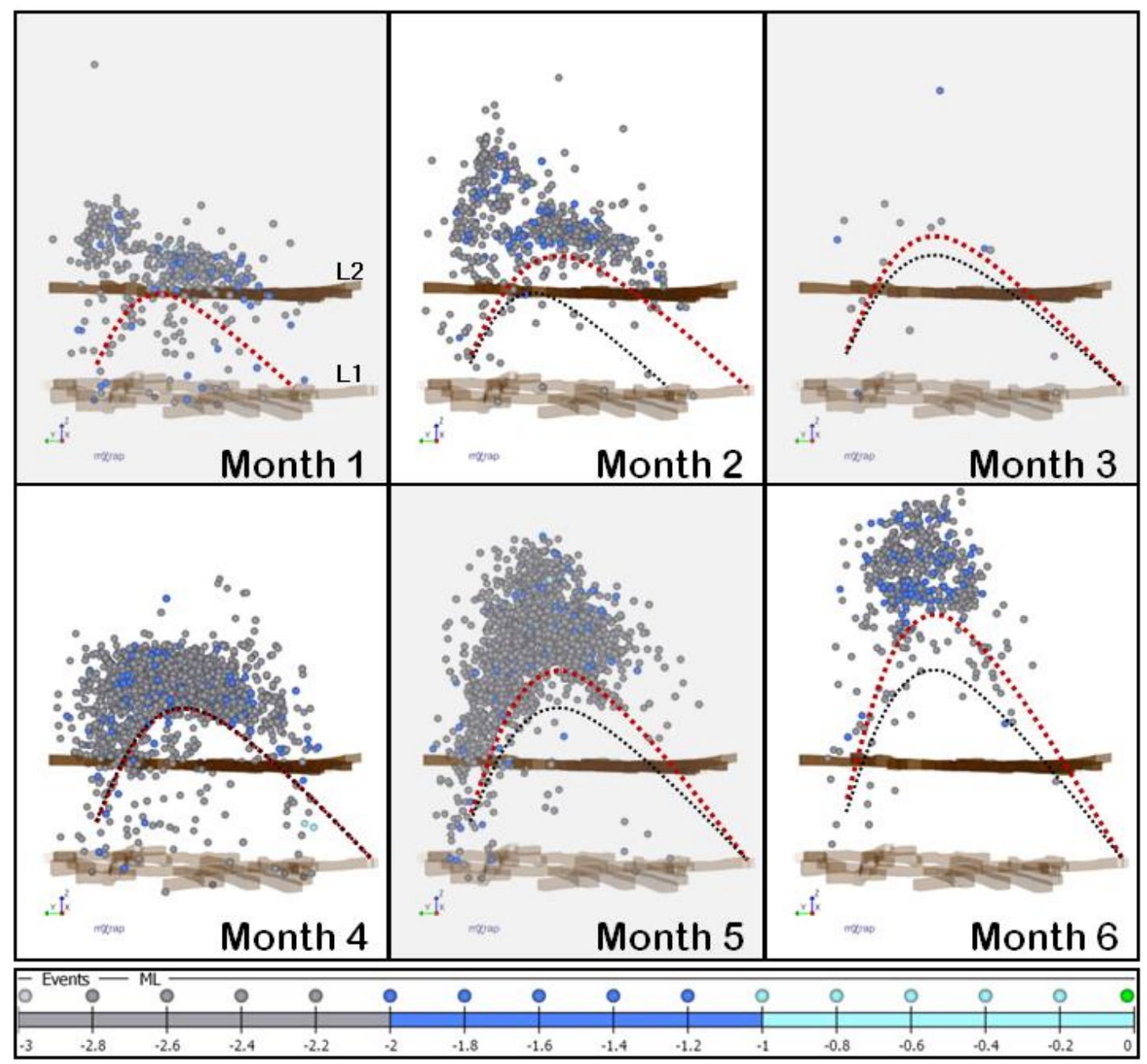

Figure 2 Isometric views of mine seismicity associated with the propagation of an unplanned rock mass cave as a deep Canadian mine. Numbers, shown in the bottom right corners, refer to sequential monthly time periods. Approximations of the cave profile are outlined for the current month (red) and previous month (black), approximately delineating the bottom of the seismogenic zone. Events are coloured according to local magnitude

In month one, the rock mass failure has surpassed cave initiation and has already propagated upwards more than $50 \mathrm{~m}$ from L1. The cave appears to approach L2, and seismic events are increasingly located just above L2. Throughout month two, seismic events continue to migrate upwards, with a noticeable aseismic zone directly above $L 2$, presumably corresponding to the zone of discontinuous deformation. As previously mentioned, month three contains very few seismic events and provides little data for further defining the cave profile.

In month four, there is arguably little to no change in the cave profile relative to months two/three. A clearly defined band of seismicity beyond the assumed cave profile is evident, and appears to reflect the spatial limits of the seismogenic zone. Month five marks the first clear appearance of a seismically defined cave apex, with a significant concentration of events above the area of historic seismic response. In month six, there is little seismic activity in the sides of the cave, with a significant concentration of seismic events 
located directly above the cave profile peak. The local rock mass surrounding the seismic apex is assumed to be relatively intact, due to a lack of preceding seismic activity in this area of the rock mass. Seismic events associated with the propagation of the cave apex, primarily in months five and six, are expected to reflect relatively high rock mass stress conditions.

\subsection{General application of apparent stress to caving data}

Figure 3 is a plot of apparent stress over time for the six months of seismic data previously outlined in Figure 2. Events are plotted according to apparent stress on the primary $y$-axis, but are coloured according to local magnitude. While larger magnitude events typically correspond to elevated apparent stress values, there is significant overlap for events $-3 \leq M_{L} \leq-1$. Just as events of the same moment, or moment magnitude, were shown to exhibit significant variation in apparent stress (Figure 1), events of the same local magnitude represent varying degrees of apparent stress (Figure 3).

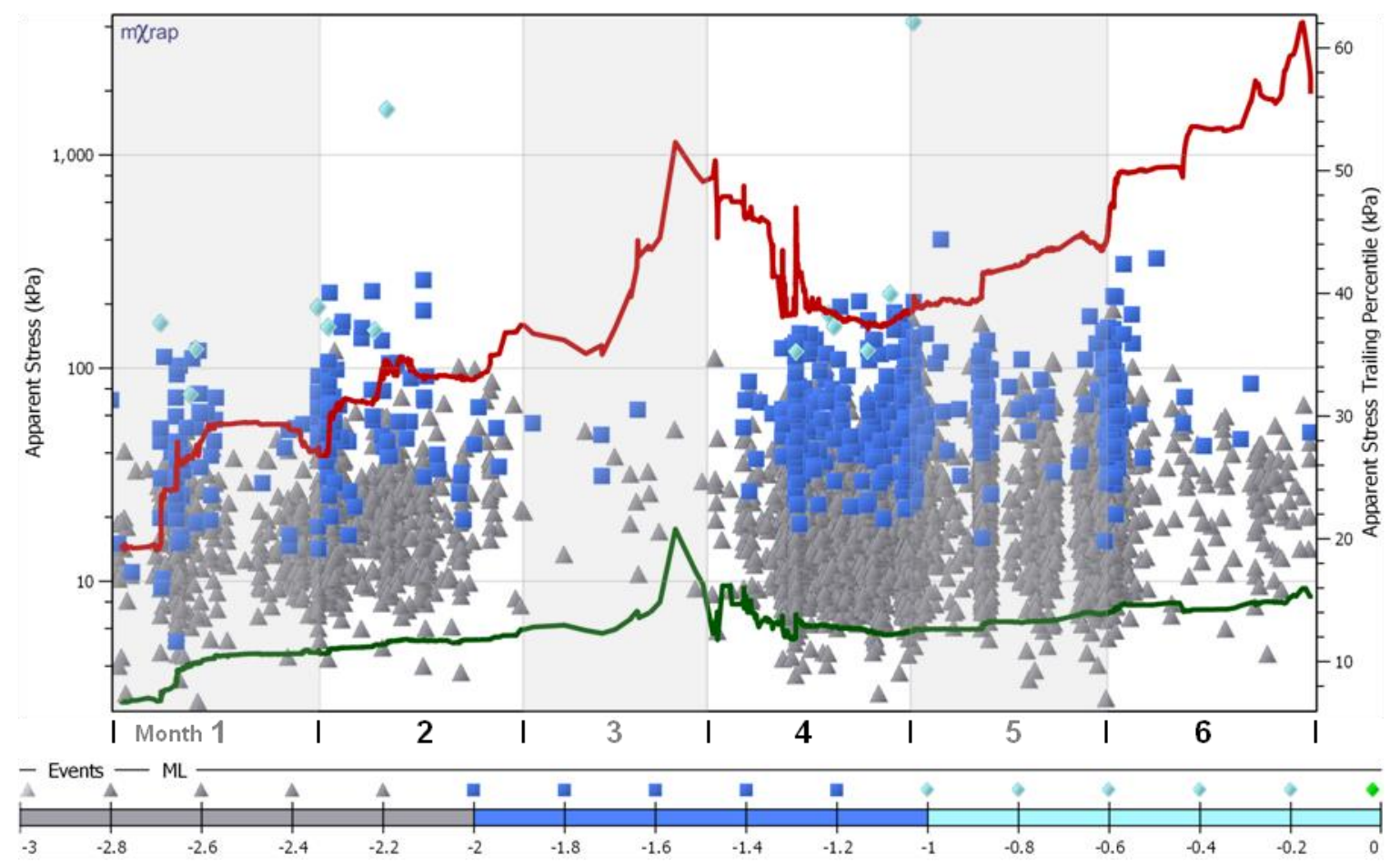

Figure 3 Plotted apparent stress over time depicting the final six months of seismic data associated with an unplanned rock mass cave in a deep Canadian mine. Events are plotted according to apparent stress (primary $y$-axis), with one-month trailing averages of the apparent stress $20^{\text {th }}$ (green) and $80^{\text {th }}$ (red) percentiles shown on the secondary $y$-axis. Events are coloured according to local magnitude. Monthly time periods refer to those shown in Figure 2

The one-month time periods previously shown in Figure 2 highlight a progression of seismicity upwards into the surrounding pseudo-continuous zone (relatively intact rock mass). This is the progression of the seismogenic zone, which is expected to contain a high-stress front. In order for this front to progress upwards, the volume of the cave increases, resulting in a proportional stress redistribution, and increase, in the surrounding rock mass. This stress increase contributes to the ongoing rock mass caving process. This is reflected in the general increase in apparent stress evident in Figure 3, particularly in the $20^{\text {th }}$ and $80^{\text {th }}$ percentiles over time. 
The use of $20^{\text {th }}$ and $80^{\text {th }}$ apparent stress percentiles, shown in green and red respectively, along the secondary y-axis in Figure 3, have previously demonstrated value in identifying increasing rock mass stress conditions and elevated seismic hazard (Brown et al. 2015). Individual apparent stress percentile values are calculated using a one-month trailing time period. In other words, the values plotted at any single point in time are primarily a reflection of the seismic events, and consequently local rock mass conditions, occurring over the preceding month. Note that one month of seismic data is considered prior to the data shown. This enables a trailing average to be displayed for month one.

In Figure 3, months two and three are of particular interest as apparent stress values continue to increase despite a significant decrease in seismic activity. This suggests that although the rate of cave propagation has decreased, the local rock mass stress conditions continue to increase. The increased degree of variability in apparent stress percentiles for month three can also be attributed to the relatively low seismic event rate.

In the final two months of data shown, months five and six, the apparent stress $80^{\text {th }}$ percentile steadily increases from less than $40 \mathrm{kPa}$ to approximately $60 \mathrm{kPa}$, while the $20^{\text {th }}$ percentile remains unchanged. This time period corresponds to the generation and progression of a rock mass cave apex (Figure 2). This apex progresses through relatively intact rock over the time period shown, requiring a stress increase to push the rock mass failure front upwards. Similar to what was observed in month three, apparent stress continues to increase in month six, despite a relative decrease in seismic activity.

Figure 4 depicts the normalised one-month trailing averages of apparent stress and daily seismic event rates for the time period previously discussed (Figures 2 and 3). Average values are normalised considering the entire seismic population associated with the unplanned rock mass cave (all data shown in Figure 1), not exclusively the data recorded during the final six months which is the focus of this paper. In other words, a value of $100 \%$ indicates the average value for that time period is equivalent to the average value of the entire seismic population (spanning approximately one year of rock mass failure). For brevity, the first six months are not included in this paper.

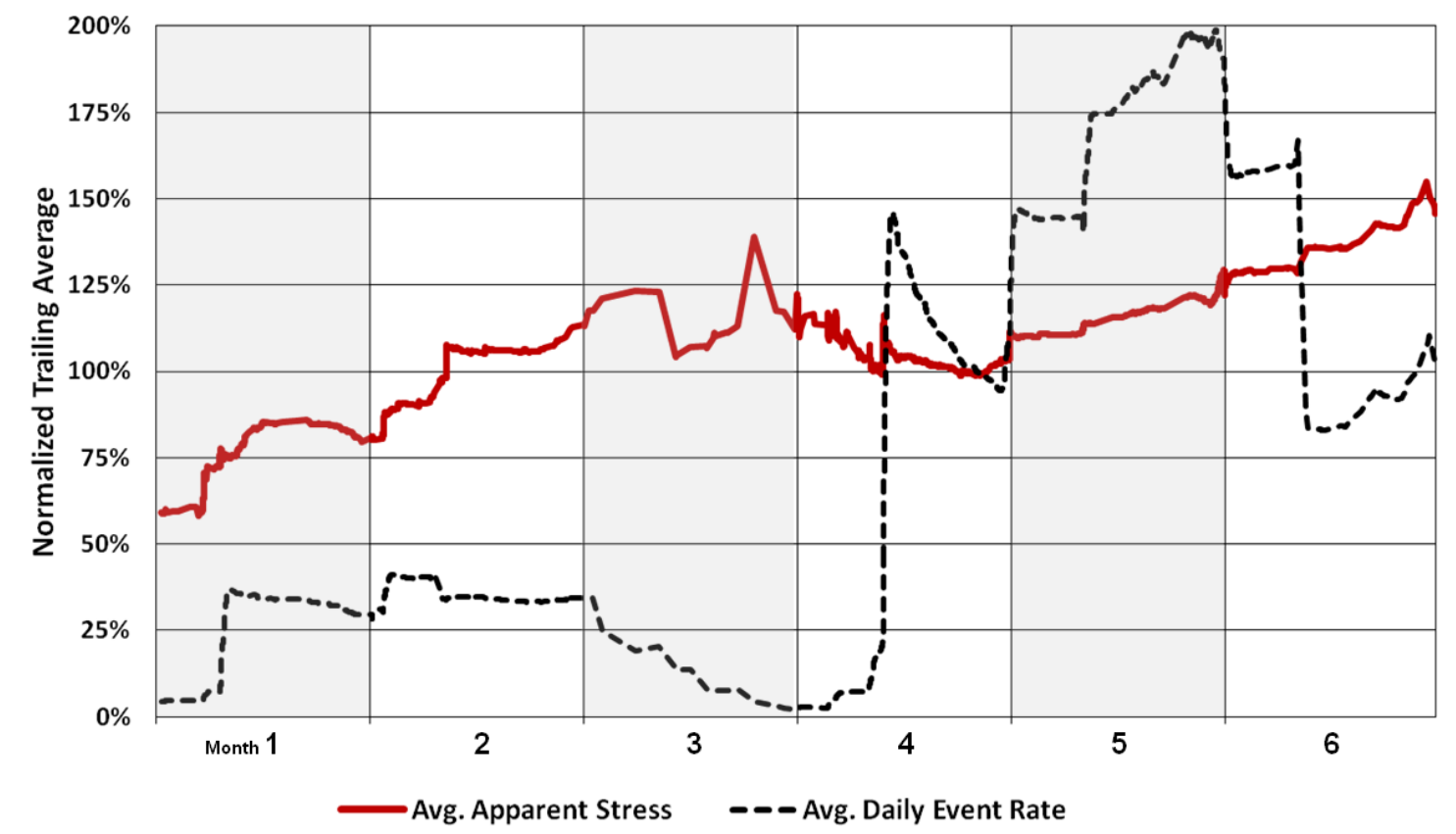

Figure 4 Normalised one month trailing averages of apparent stress and daily seismic event rates for the final six months of seismic data associated with an unplanned rock mass cave in a deep Canadian mine. Monthly time periods refer to those shown in Figure 2 
Of particular interest in Figure 4 are the distinct differences in trends over time of average apparent stress and average daily event rates. Although the average daily event rates remain relatively constant in months one and two, there is a noticeable increase in apparent stress in months one and two, exceeding $100 \%$ of the overall average apparent stress. In month three, the daily event rates drastically decrease, as is evident in Figures 2 and 3. However, apparent stress values remain above $100 \%$ of the overall average. Part way through month four, a spike in average daily event rates occurs, but is not significantly reflected in the average apparent stress. This is true for other event rate spikes occurring throughout the latter months of the entire time period considered. When average daily event rates exceed $100 \%$ of the average in month four, and into months five and six, there is no direct impact on the average apparent stress.

\subsection{Identifying a migrating high-stress front over time using apparent stress}

Cumulative seismic source parameters can provide insight into rock mass failure processes (Hudyma et al. 2008). When evaluating cumulative parameters, it is important to consider the influence of the number of individual seismic events summed - cumulative number of events. Figure 5 depicts grid-based cumulative parameter maps of apparent stress (a) and number of events (b) for the six-month caving time period considered. For all grid-based maps shown in this paper (Harris \& Wesseloo 2015), an arbitrary grid spacing of $5 \times 5 \times 5 \mathrm{~m}$ is used to ensure a sufficient resolution. A search radius of $8 \mathrm{~m}$, equivalent to the median location error of the dataset, is used to form seismic populations surrounding each grid point. Cumulative parameter maps shown depict all seismic data related to the rock mass cave for the time period considered, not long sections through the cave. Marker transparencies have been manipulated such that relatively high values are visible through relatively low values.

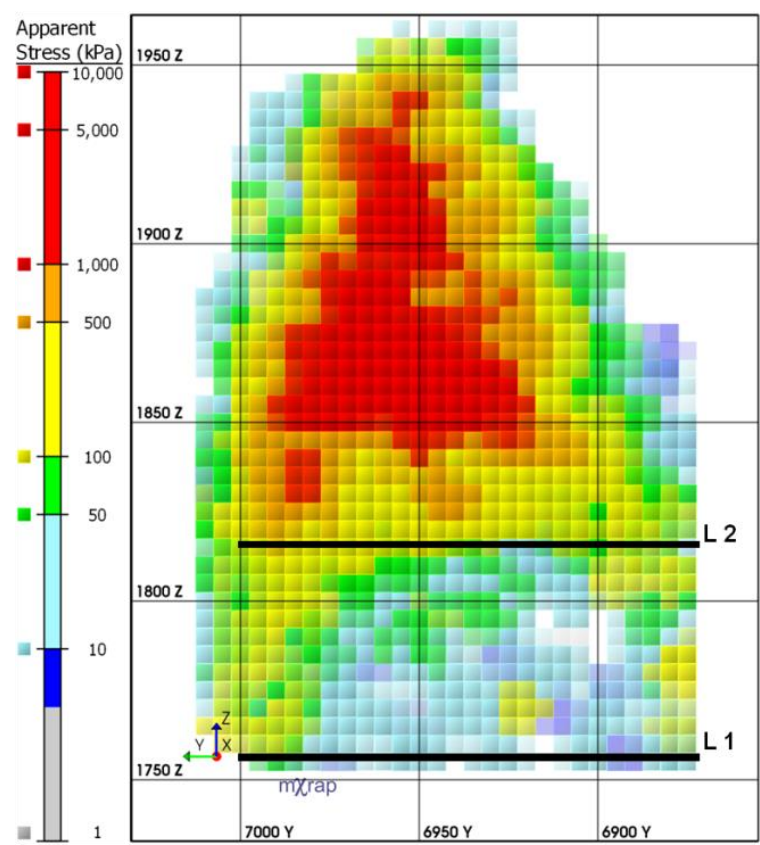

(a)

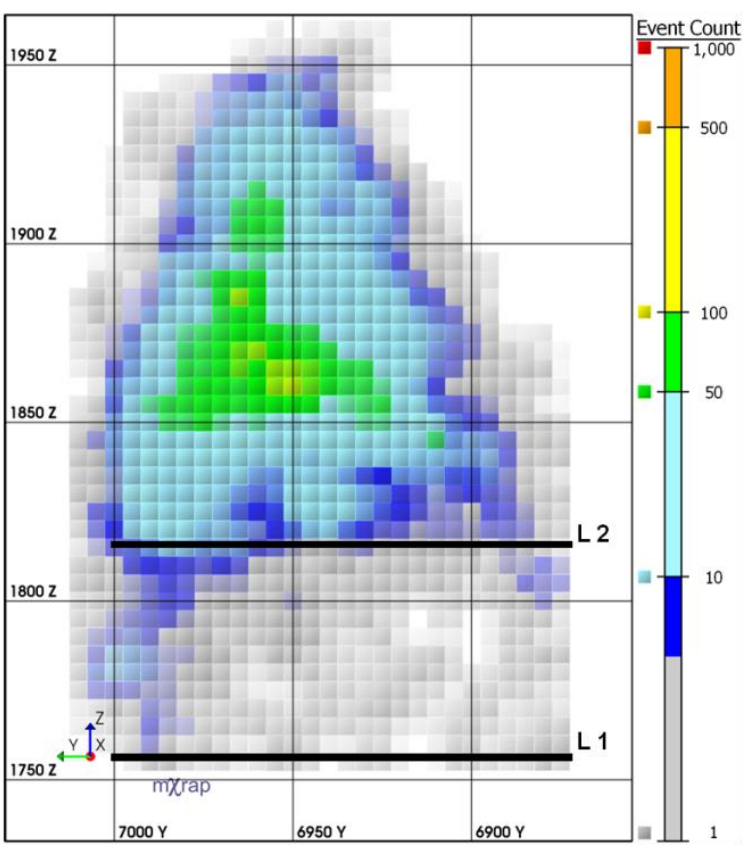

(b)

Figure 5 (a) Grid-based cumulative parameter maps of apparent stress; and, (b) Number of events for the final six months of seismic data associated with an unplanned rock mass cave in a deep Canadian mine. Three-dimensional grid spacing is $5 \times 5 \times 5 \mathrm{~m}$, with an $8 \mathrm{~m}$ search radius used for forming individual seismic populations. Discrete colour changes correspond to roughly a half an order of magnitude increase, either in cumulative apparent stress or number of events, as indicated by the corresponding legends. Two mining levels are intersected by the cave, arbitrarily shown as L1 and L2 
The two maps shown in Figure 5 are not intended for direct comparison, as the effects of individual events on the overall cumulative sums are not proportional for the two parameters, but simply as a means of ensuring trends in cumulative apparent stress are not direct reflections of the number of local seismic events. Discrete colour changes correspond to roughly a half an order of magnitude increase, either in cumulative apparent stress or cumulative number of events. In a study of cave seismic data from Telfer mine (Abolfazlzadeh \& Hudyma 2016), individual events with apparent stress values exceeding $30 \mathrm{kPa}$ were considered indicative of relatively high-stress conditions in the cave peak, or apex of the seismogenic zone. Only $3 \%$ of events recorded at Telfer had apparent stress values exceeding $30 \mathrm{kPa}$. For the caving data considered in this paper, $27 \%$ of events have an apparent stress greater than $30 \mathrm{kPa}$. Cumulative apparent stress values in excess of 500 to $1,000 \mathrm{kPa}$, shown as orange and red respectively, are considered high and indicative of a high-stress front.

For the six-month time period considered in Figure 5, a high-stress zone (cumulative apparent stress greater than $500 \mathrm{kPa}$ ) spans approximately $100 \mathrm{~m}$ from 1,850z to 1,950z. This stress zone closely resembles the overall profile of a rock mass cave, with a relatively wide base and a peak at the highest point. The cumulative number of events map contains a significant region of relatively high event counts (cumulative number of events greater than 50 ), spanning for approximately $50 \mathrm{~m}$ from $1,850 \mathrm{z}$ to $1,900 \mathrm{z}$. This region is indicative of where the highest event concentrations occurred throughout the cave propagation process. In context, this area typically exhibits cumulative apparent stress values in excess of $1,000 \mathrm{kPa}$, corresponding to an average apparent stress for individual seismic events between approximately 10 and $20 \mathrm{kPa}$ (assuming 50 to 100 individual seismic events).

Figures 6 and 7 are sequential cumulative parameter maps of apparent stress for the individual monthly time periods previously discussed (shown in Figure 2). This shows the migration of the high-stress front, inferred from relatively high values of cumulative apparent stress, identified over time. In month one, the highest cumulative apparent stress values are more than $500 \mathrm{kPa}$, or two orders of magnitude greater than the lowest. For this time period, high apparent stress is indicative of a relatively high-stress front located above L2, and extending upwards approximately $15 \mathrm{~m}$. Although there is a large approximate seismogenic zone identified where seismic events occur, there is only a small isolated area in proximity to the cave profile peak where relatively high cumulative apparent stress values are observed.

In month two, the high-stress front (as identified through cumulative apparent stress) migrates a $20 \mathrm{~m}$ upwards, approaching $1,850 \mathrm{z}$. As was seen in month one, the high-stress front appears to locate above the peak of the cave profile. Although the largest quantities of seismic events are associated with the upwards cave propagation between $7,000 y$ and $6,950 y$, this is not the region with the highest cumulative apparent stress, indicating the highest rock mass stress is not a direct reflection of the largest event concentrations. A small area void of seismic activity is visible between $L 2$ and the high-stress front. This likely reflects the migration of the cave void, and/or discontinuous deformation zone, beyond L2. 


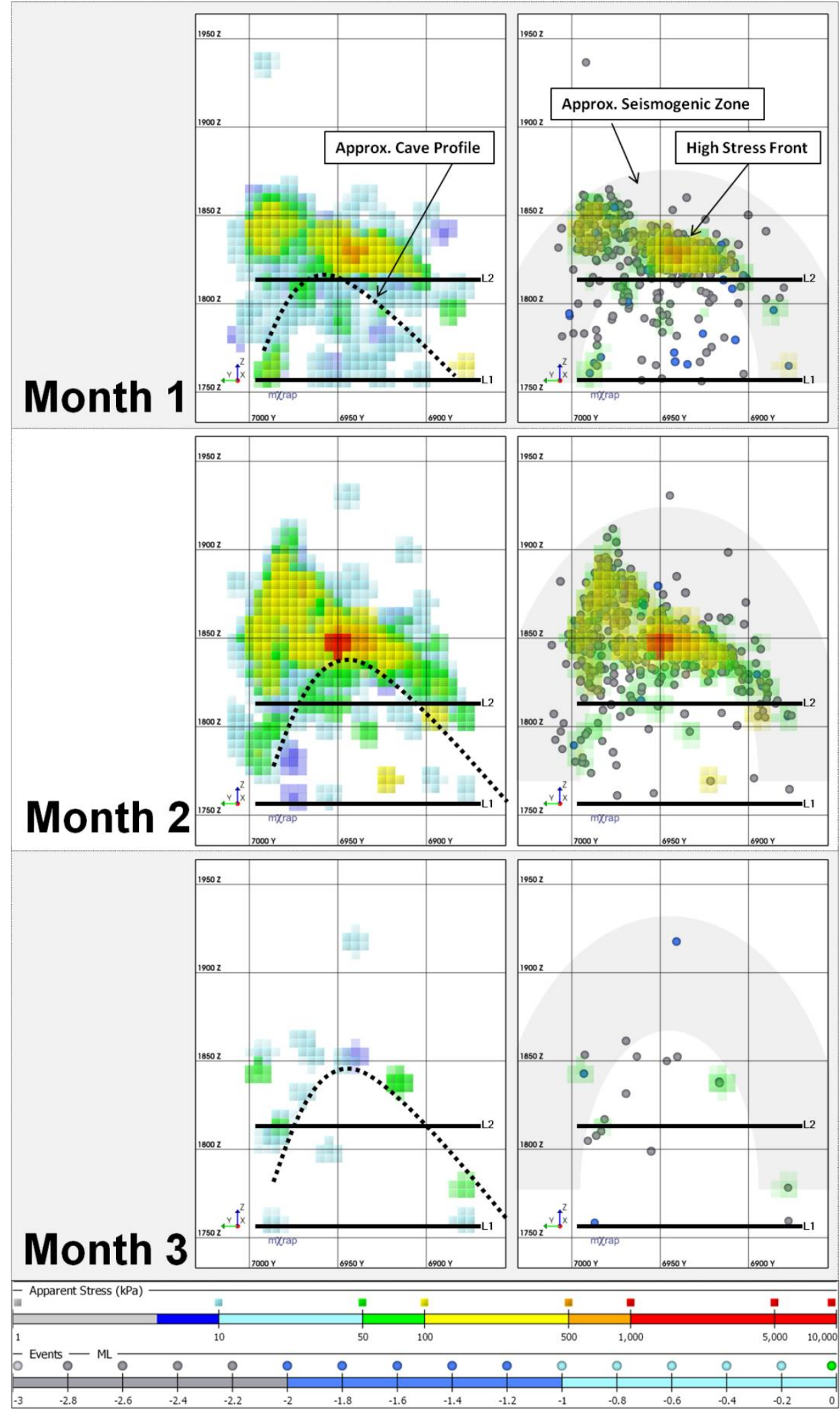

Figure 6 Grid-based cumulative parameter maps of apparent stress for months one, two and three, as previously defined in Figures 2, 3 and 4. The full map is shown (left), along with a depiction of the seismic event locations and largest cumulative apparent stress values (right). Discrete colour changes in cumulative apparent stress correspond to roughly a half an order of magnitude increase. An approximate seismogenic zone, as dictated by the event locations, is shown in grey (right). Two mining levels are intersected by the cave, arbitrarily shown as L1 and L2 


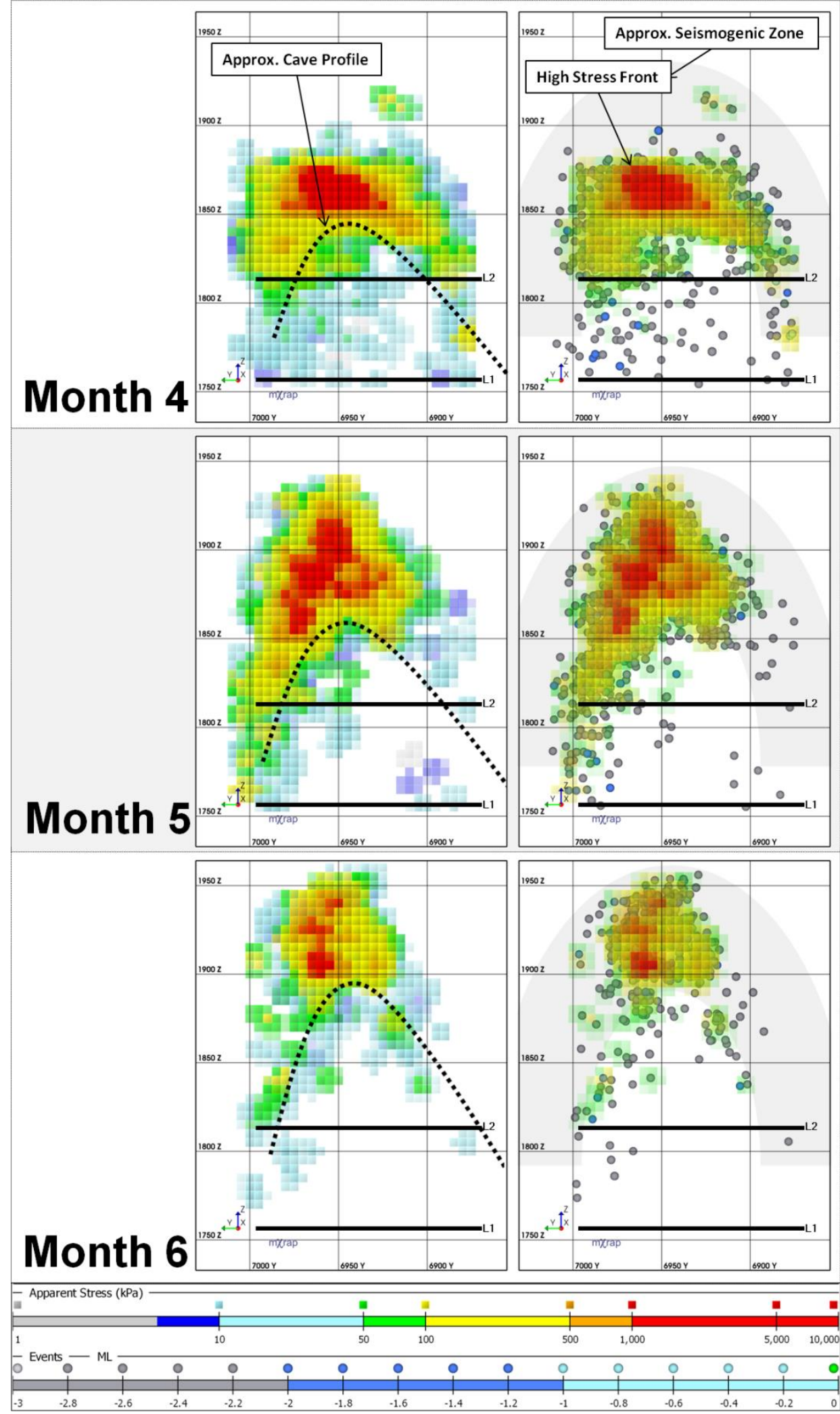

Figure 7 Grid-based cumulative parameter maps of apparent stress for months four, five and six, as previously defined in Figures 2, 3 and 4. The full map is shown (left), along with a depiction of the seismic event locations and largest cumulative apparent stress values (right). Discrete colour changes in cumulative apparent stress correspond to roughly a half an order of magnitude increase. An approximate seismogenic zone, as dictated by the event locations, is shown in grey (right). Two mining levels are intersected by the cave, arbitrarily shown as L1 and L2 
Significantly reduced seismic event rates in month three prevent the identification of the rock mass high-stress front. Events continue to plot within and surrounding the approximate seismogenic zone. However, concentrations are not sufficient for identifying trends in cumulative seismic source parameters. In Figure 4, which considers a normalised average apparent stress, data trends in month three are still indicative of relatively high rock mass stress, irrespective of the decrease in event rate. This suggests that average values may provide more insight into rock mass conditions, compared to cumulative parameters, for time periods with relatively few seismic events.

Month four (shown in Figure 7), depicts a significant increase in the rate of cave propagation relative to the preceding three months (shown in Figure 6). The approximate cave profile extends to nearly $1,850 z$, and is located below a comparatively continuous zone of cumulative apparent stress greater than $100 \mathrm{kPa}$ (yellow). The high-stress front, where cumulative apparent stress exceeds $1,000 \mathrm{kPa}$, begins around 1,850z and extends upwards approximately $25 \mathrm{~m}$. Consistent with previous observations, the high-stress front locates directly above the apex of the cave profile.

As previously discussed, month five is the first observation of a definitive arch shape in the seismic response, with a significant quantity of seismic events located above 1,900z. Unplanned rock mass caves in mines, considering both drift and stope scale, typically stabilise in an arch under gravitational loading (Ran \& Disley 2004). The high-stress front, extending from approximately $1,850 z$ to $1,925 z$ in month five, also changes profile to resemble more of an arch shape with a definitive peak.

In month six, the final time period considered, seismic events are highly concentrated above 1,900z, with relatively small and isolated rock mass volumes where cumulative apparent stress exceeds $1,000 \mathrm{kPa}$. The rock mass cave sides appear to have stabilised relative to the apex during this final time period considered. An area void of seismic activity is located directly below the high-stress front (and seismic event concentration), which is assumed to approximate the final cave profile.

During the entire six months of seismic data considered in Figures 6 and 7, the unplanned rock mass cave propagates upwards more than $75 \mathrm{~m}$. A high-stress front, located within but not spanning the entire range of recorded rock mass failure (seismogenic zone), continually migrates upwards as the cave propagates. This front, as identified using cumulative apparent stress, appears to locate directly above the caved rock mass apex both before and during initial cave stabilisation, as shown in month six.

\section{Conclusion}

Data from the unplanned rock mass cave follows the model for block caving mines as outlined by Duplancic and Brady (1999). Seismic data appears to trace a zone of fracturing above the cave, referred to as the seismogenic zone. The highest apparent stress values are observed in the apex of the cave.

This paper has demonstrated how trends in apparent stress of mine seismic data, associated with an unplanned rock mass cave in a deep Canadian mine, can provide insight into relative rock mass stress conditions; specifically the identification and migration of high-stress fronts over time. In the case of unplanned stope back caves, the location of relatively high rock mass stress within the seismogenic zone may be of increased importance, as it can be used to mitigate seismic risk when implementing control measures.

\section{Acknowledgement}

The authors thank the staff at the Australian Centre for Geomechanics for use and support of their mXrap seismicity data analysis software.

Funding for this research was provided by Agnico Eagle, KGHM International, Vale, the Australian Centre for Geomechanics, and the Natural Sciences and Engineering Research Council. 


\section{References}

Abolfazlzadeh, Y \& Hudyma, M 2016, 'Identifying and describing a seismogenic zone in a sublevel caving mine', Rock Mechanics and Rock Engineering, vol. 49, no. pp. 3735-3751.

Brown, L \& Hudyma, MR 2017, 'Identification of stress change within a rock mass through apparent stress of local seismic events', Rock Mechanics and Rock Engineering, vol. 50, no. 1, pp. 81-88.

Brown, LG, Turcotte, P \& Hudyma, MR 2015, 'Seismic hazard assessment using apparent stress ratio', in Y Potvin (ed.), Proceedings of the International Seminar on Design Methods in Underground Mining, Australian Centre for Geomechanics, Perth, pp. 123-134.

Butcher, R 2003, 'Caving geomechanics', Proceedings of ACG Seminar 0309, Australian Centre for Geomechanics, Perth.

Domanski, B \& Gibowicz, SJ 2008, 'Comparison of source parameters estimated in the frequency and time domains for seismic events at the Rudna copper mine, Poland', Acta Geophysica, vol. 56, no. 2, pp. 324-343.

Duplancic, P \& Brady, BH 1999, 'Characterization of caving mechanisms by analysis of seismicity and rock stress', in G Vouille \& $P$ Berest (eds), Proceedings of the Ninth International Congress of Rock Mechanics, International Society for Rock Mechanics and Rock Engineering, Lisbon, pp. 1049-1053.

Gibowicz, SJ, Harjes, HP \& Schafer, M 1990, 'Source parameters of seismic events at Heinrich Robert mine, Ruhr Basin, Federal Republic of Germany: Evidence for nondouble-couple events', Bulletin of the Seismological Society of America, vol. 80, no. 1, pp. 88-109.

Gibowicz, SJ, Young, RP, Talebi, S \& Rawlence, DJ 1991, 'Source parameters of seismic events at the underground research laboratory in Manitoba, Canada: Scaling relation for events with moment magnitude smaller than -2', Bulletin of the Seismological Society of America, vol. 81, no. 4, pp. 1157-1182.

Glazer, SN 2016, 'Palabora mine caving process as revealed by induced seismicity', Mine Seismology: Data Analysis and Interpretation, Springer International Publishing, Basel.

Harris, PC \& Wesseloo, J 2015, mXrap, version 5, computer software, Australian Centre for Geomechanics, The University of Western Australia, Perth, https://www.mxrap.com

Hudyma, MR 2008, Analysis and Interpretation of Clusters of Seismic Events in Mines, PhD thesis, University of Western Australia, Perth.

Hudyma, MR, Potvin, Y \& Allison, D 2008, 'Seismic monitoring of the Northparks lift 2 block cave - part 1 undercutting', The Journal of South African Institute of Mining and Metallurgy, vol. 108, no. 7, pp. 405-419.

Mendecki, AJ 1993, 'Real time quantitative seismology in mines', in RP Young (eds), Proceedings of the Third International Symposium on Rockbursts and Seismicity in Mines, CRC Press, Boca Raton, pp. 287-295.

Ran, J \& Disley, N 2004, 'Back caving mechanism and preventive measures for deep open stopes - case studies', Canadian Institute of Mining and Metallurgy Annual General Meeting 2004, Canadian Institute of Mining, Metallurgy \& Petroleum, Westmount.

Reyes-Montes, JM, Sainsbury, BL, Pettitt, WS, Pierce, M \& Young, RP 2010, 'Microseismic tools for the analysis of the interaction between open pit and underground developments', in Y Potvin (ed.), Proceedings of the Second International Symposium on Block and Sublevel Caving, Australian Centre for Geomechanics, Perth, pp. 119-131.

Simser, BP, Falmagne, V, Gaudreau, D \& MacDonald, T 2003, 'Seismic response to mining at the Brunswick mine', Canadian Institute of Mining and Metallurgy Annual General Meeting 2003, Canadian Institute of Mining, Metallurgy \& Petroleum, Westmount.

van Aswegen, G \& Butler, AG 1993, 'Applications of quantitative seismology in South African gold mine', in RP Young (eds), Proceedings of the Third International Symposium on Rockbursts and Seismicity in Mines, CRC Press, Boca Raton, pp. 261-266.

Wyss, M \& Brune, JN 1968, 'Seismic moment, stress and source dimensions for earthquakes in the California-Nevada region', Journal of Geophysical Research, vol. 73, no. 14, pp. 4681-4694.

Young, DP 2012, Energy Variations in Mining-Induced Seismic Events using Apparent Stress, MSc thesis, Laurentian University, Sudbury. 